\title{
Integrative river basin management: challenges and methodologies within the German planning system
}

\author{
Mariele Evers ${ }^{1}$
}

Received: 7 February 2016/ Accepted: 2 July 2016/Published online: 19 July 2016

(C) The Author(s) 2016. This article is published with open access at Springerlink.com

\begin{abstract}
Integrated river basin management (IRBM) is recently fostered in the European Union mainly by two framework directives which were established in order to realise sustainable and effective river basin management and aiming for integrated approaches on a river basin scale. One is the water framework directive which objective is to assess water quality and achieve a good status for all water bodies. The other one is the flood risk management directive on the assessment and management of flood risks. This paper discusses the potential synergies of the two directives against IRBM in general and describes European experts' views which were formulated as recommendations. The status of the water bodies and water governance system in Germany are described and critically reflected against the experts' recommendations. Potential methodological approaches which were developed and tested in German case studies are presented and discussed in the light of IRBM with focus on identifying and using crosssectoral synergies. The analysis reveals shortcomings in IRBM approaches in Germany and potentials for identification and use of synergies if certain framework, concept approaches and methodological approaches would be used.
\end{abstract}

Keywords Integrated river basin management .

Cross-sectoral synergies · Methodologies .

Water governance in Germany

This article is part of a Topical Collection in Environmental Earth Sciences on "Water in Germany", guest edited by Daniel Karthe, Peter Chifflard, Bernd Cyffka, Lucas Menzel, Heribert Nacken, Uta Raeder, Mario Sommerhäuser and Markus Weiler.

Mariele Evers

mariele.evers@uni-bonn.de

1 Geography Department, University of Bonn, Meckenheiemr Allee 166, 53115 Bonn, Germany

\section{Introduction}

Integrated river basin management (IRBM) is not a new topic, but interest in it has increased recently. In Europe, the most notable facts are on the one hand the signing of the UNECE Convention on the Protection and Use of Transboundary Watercourses and International Lakes (UNECE 1992) with entry into force of amendments in February 2013 and on the other hand the implementation of two legal frameworks on water quality and flood risk management.

River basin management can be considered as the integration of planning and management of water resources, sustainable development and strategies on a river basin level (Bandaragoda and Babel 2010).

IRBM is based on the principle that naturally functioning river basin ecosystems, including accompanying wetlands and groundwater systems, are the source of freshwater. Therefore, management of river basins must include the maintenance of ecosystem functioning as a paramount goal. On the other hand, IRBM includes human interests and managing activities on the basin scale. In terms of the WWF-project "Managing Rivers Wisely", key issues for a comprehensive approach for an IRBM and its successful implementation involve inter alia (WWF 2003):

- The integration of policies, decisions and costs across sectoral interests such as industry, agriculture, urban development, navigation, fishery management and conservation, amongst other things through poverty reduction strategies;

- A long-term vision for the river basin, agreed to by all the major stakeholders, strategic decision-making at the river basin scale and active participation by all relevant stakeholders in well-informed and transparent planning and decision-making processes; and 
- A solid basis of knowledge of the river basin and the natural and socio-economic forces that influence it.

Hence, there is a demand for integration with long-term visions and coordination between basin and sub-basins to which all major stakeholders should have agreed; this should have a solid financial foundation and be based on solid knowledge of the river basin and the interrelationships involved.

In the European Union, two European directives which were established in order to realise sustainable and effective river basin management are aiming for integrated approaches on a basin scale.

In force since 2000, the water framework directive (WFD) has made river basin management obligatory for all 27 member state governments to be introduced universally according to a strict timetable. The Directive 2000/60/EC of the European Parliament and of the Council of 23 October 2000 aims at establishing a framework for community action in the field of water policy (Water Framework Directive, WFD) (EC 2000). Directive 2007/60/EC of the European Parliament and Council of 23 October 2007 on the assessment and management of flood risks (Flood Directive, FD) (EC 2007) entered into force in 2007. A framework directive of the European Union is a legislative act, which requires the implementation into national legislation by member states and the achievement of a particular result.

The preamble of the FD states that these directives are parts of integrated river basin management.

The objective of this paper is a. if and how both directives can be coordinated in a coherent way towards an integrated river basin management and b. to assess if and how IRBM is applied in Germany and c. to present possible scientific approaches for IRBM. This paper is structured as follows: (1) a short characterisation of WFD and FD and identifying synergies, (2) requirements and recommendations for a coherent coordination from European expert views, and (3) analysis of the German RBM situation against the background of requirements of WFD and FD and expert recommendations, (4) an illustration of methodological approaches for IRBM and a summary and discussion of potential as well as need for further research.

\section{The WFD and FD in the light of IRBM}

\section{A brief characterisation of WFD and FD}

In 2000, the EU Water Framework Directive (WFD) was adopted. On the European level, it was the beginning of the implementation of river basin management in all member states ${ }^{1}$ (in some countries, such as France, this had already been established earlier). The overall goal of the WFD is the protection and sustainable use of water resources. The central items of concern are surface water and groundwater, which have to achieve "good" ecological and chemical status by 2015 .

The WFD standardises European water protection by replacing seven former individual directives. For detailed description of the characteristics and synergies, please see Evers and Nyberg (2013).

The WFD follows an ecosystem based approach which addresses, in addition to the quality of rivers, lakes, transitional waters, coastal waters and groundwaters, pressures within the basin that may cause deterioration or provide risk to water and its ecology (Griffiths 2002). Since the issue of floods is barely touched by the WFD another directive, the Flood Risk Directive (FD) was established to deal with this aspect of water management. The FD relates in many points to the earlier published Water Framework Directive, for example, with respect to management units at the river basin level, a coordinated time plan and the coordination of participation processes.

The implementation of the FD has to be aligned with the implementation of the Water Framework Directive (see e.g. Holzwarth 2002; Mostert and Junier 2009; Evers and Nyberg 2013; EC 2014).

\section{The Flood Directive's aim is}

“[...] to establish a framework for the assessment and management of flood risks, aiming at the reduction of the adverse consequences for human health, the environment, cultural heritage and economic activity associated with floods in the Community" (EC 2007, Article 1).

Under the directive, member states should first carry out a preliminary assessment to classify and identify the river basins and associated coastal areas at risk of flooding (Article 4). For such zones, they would then need to produce flood hazard maps and flood risk maps for areas with potentially significant flood risks (Art. 6). These maps have to indicate flood extent, water depths and, where appropriate, flow velocities or the relevant water flows in the following three scenarios:

(a) Floods with a low probability or extreme event scenarios;

\footnotetext{
${ }^{1}$ According to the WFD, Article 2, river basin refers to "the area of land from which all surface run-off flows through a sequence of streams, rivers and, possibly, lakes into the sea at a single river mouth, estuary or delta." (EC 2000).
} 
(b) Floods with a medium probability (likely return period 100 years);

(c) Floods with a high probability, where appropriate.

The flood risk maps have to show the potential adverse consequences in these three scenarios. Even more interesting, from an integration point of view, is the need for flood risk management plans (FRMP) (Article 7) by 22 December 2015 (and respectively 2021 and 2027 within the next management cycles) as an important instrument for integrative flood risk (and river basin) management. The FD requires that a flood risk management plan at the level of river basin district or sub-river basin is developed which should address all phases of the flood management cycle and focus on prevention, protection and preparedness. The member states shall ensure an active involvement of all interested parties in the production, review and updating of the FRMP. This active involvement has to be coordinated with the active parties (cf. Article 14 of WFD).

The FRMP have to contain "appropriate objectives" for the management of flood risks, focusing on the reduction of potential adverse consequences of flooding for human health, the environment, cultural heritage and economic activity, and, if considered appropriate, on non-structural initiatives (such as information, prediction, etc.) and/or on the reduction of the likelihood of flooding [Article 7(2)]. The plans also have to include measures for meeting these goals. Furthermore, they have to take relevant aspects into account, such as costs and benefits, areas with a potential for retaining flood water, such as natural floodplains, the environmental objectives of the WFD, soil and water management, spatial planning, land use, nature conservation, navigation and port infrastructure.

\section{Synergies between WFD and FD}

The development of RBMP under the WFD and of FRMP under the FD can be regarded as elements of river basin management. FD Recital 17 states that "the two processes should therefore use the mutual potential for common synergies and benefits, having regard to the environment objectives of the WFD, ensure efficiency and wise use of resources, while recognising that the competent authorities and management units might be different under FD and WFD".

There are many examples for synergies between the two directives. An important example is the quality component (one of the relevant parameters in the WFD which describes inter alia the status of water bodies) of rivers, river banks and riparian areas and how it affects water quality. Amongst other things, the hydromorphology of a water body can be managed to provide habitats and it can increase the water retention potential and reduction of flow velocity in order to reduce flood risk (e.g. lowering the water level and/or damage potential).

For both directives similar instruments such as management plans are required (see above).

Coordination of the two directives is needed in terms of RBM because of:

- Overlapping of legal and planning instruments;

- Planning and management of identical geographical units;

- Implications and dependences/interrelations of goals;

- Synergies and efficiency of implementation of measures.

FD and WFD are both "goal-oriented legislation" which means that both directives are characterised by:

- Meeting certain goals described in the directives;

- The introduction and the mandatory use of certain instruments and processes;

- Involvement of interested stakeholders/parties;

- Similar planning process within a given timescale;

- Plans serve as conceptual basis for meeting the goals.

However, despite of all these similarities, the two directives aim for different goals and have different priorities. Different organisational bodies are to be involved, and there are partly different bodies and stakeholders affected or responsible.

The WFD can help in supporting developing targets for floodplains. This is especially the case if WFD instruments are coupled and coordinated with instruments of nature conservation and environmental and spatial planning.

Aspects of flood risk management should be taken into consideration in the WFD because flood risk is evidently dependent on interrelations in the river basin as described earlier. Another reason for incorporating flood aspects into river basin management is that the hydromorphological elements river continuity and morphological conditions can support better water retention in the floodplain. Measures for a better groundwater recharge can be of assistance in achieving a good quantitative status of groundwater. And, again, appropriate land use is not only useful for good (ground)water quality but also for improved water retention potential in the catchment. Further potential synergies between the WFD and flood risk management are:

- As they have already been characterised for the WFD, river basins are clearly differentiated and defined;

- Administrative and coordinating competences are defined;

- Standardised data on river and morphological quality and, in particular, deficits are available;

- Data on groundwater levels have been accumulated; 
- large-scale land use data are available (e.g. based on Landsat satellite data);

- Relevant protected areas have been listed and mapped in connection with water bodies;

- Hydrological data have been compiled;

- Main groundwater extraction and critical areas are known;

- Participation of interested parties is required for both directives.

Thus, flood-relevant measures should be included in management plans and programmes of measure. For example, the following should be considered:

- Rise of retention potential;

- Status improvement of river structures;

- Improvement of groundwater recharge;

- Improvement of the chemical status of the groundwater due to more infiltration than direct runoff.

Additionally, planning targets for flood risk reduction on the river basin scale can be identified. Some examples can be:

- Identification of possible dike shifting areas or restoration of floodplains;

- Planning goals and focal points for urban development;

- Declaration of maximal sealing rates in urban areas;

- Mapping of de-sealing potentials;

- Design of possible measures to rise the potential retention in the catchment;

- Mapping of possible restoration areas, e.g. as pools for compensation measures;

- Mapping of flood protection measures.

Notwithstanding the fact that floodplains are not specifically mentioned, the implementation of the WFD will certainly have some effects on or interrelations with floodplain management:

- Improvement of the natural environment in aquatic and semi-aquatic areas through better water quality and quantity measures;

- Supporting of nature conservation goals in NATURA 2000 areas and in national protected areas that have a close relation to water as Flora-Fauna-Habitat Directive (EC 1992) areas and areas designated by the Conservation of Wild Birds Directive have to be considered;

- Minimising of river training and support of efforts for restoration with a view to improving the hydromorphology;

- Re-establishing of natural circumstances in wetlands (e.g. change of land use to recover water quality);

- Contribution to protection and development of biodiversity, e.g.
- Improvement of the river structure and dike relocation in order to enlarge floodplains;

- Consideration of water-dependent land ecosystems;

- A contribution to the network of interlinked biotopes (e.g. improving connectivity for better exchange of aquatic populations along the whole riverside, improvement of the river structure, water quality and riverbanks along with ecotones;

- Enhances the value of the natural scenery;

- Additional measures like restoration of wetlands and floodplains;

- Implementation of good agricultural practice by including it in programmes of measures.

The previous sections have shown the challenges of the joint coordination of the two directives aiming at different goals. At the same time, great potential exists when considering synergies between the directives. Following, the views of European experts regarding those synergies will be described.

\section{European experts' views on synergies between WFD and FD}

From 2008 to 2012, a European Research project, called "Strategic Water Alliance of Water Management Actions (SAWA)" (www.sawa-project.eu) was carried out. Twenty-two academic and non-academic institutions from five countries (Norway, Sweden, UK, Germany and the Netherlands) were working on water and flood related issues. During one of the project conferences, the author elicited views on potential synergies between the two directives by getting feedback from water experts.

The first elicitation of the expert views were conducted via a workshop which was integrated in a 2-day SAWA conference in Karlstad, Sweden 23-25 March 2009. The workshop's topic was about synergies and conflicts of FRMP with the objectives and measures of the river basin management plans (RBMP) which are required to be developed by the WFD. Seven participants from four countries (Sweden, Norway, the Netherlands and Germany, four male, three female participants) took part in the two hour session. The participants were representing national and regional authorities and universities dealing with water management related issues. The experts were discussing intensively and agreed upon a range of important aspects and recommendations. Minutes were taken for this session as well as presented and agreed upon in a plenary session.

The second analysis was undertaken by using a questionnaire on synergies and conflicts between WFD and FD. During the same conference, a questionnaire was distributed to all participants in a plenary session. 
The following questions were included in the questionnaire: (1) Where do you consider the most important synergies/reasons for integration of WFD and FD? (2) Where do you consider the most important hindrances/conflicts in coordinating WFD and FD? (3) Examples for synergies or possible approaches. The questionnaire included tick boxes and also frees space for individual comments.

The questionnaires were filled in by 31 persons from five countries (Sweden, Norway, the Netherlands, UK and Germany) who were representing diverse institutions water management authorities, water boards, universities, planning authorities, chambers of agriculture, etc. A good mix of gender (ca. $40 \%$ female and $60 \%$ male respondants) and experience level was represented in the group. The respondents had roughly $15 \mathrm{~min}$ to fill in the questionnaire.

Based on the results of the expert agreed upon recommendations and the empirical material from the questionnaire, the following recommendations were formulated by the author of this paper:

\section{Recommendation 1: Communication and coordination}

- A clear communication and effective coordination of the implementation of both directives must be guaranteed.

- There is a need for a structured exchange of data and information, common databases, web-features and mapping services, using the same technical standards (e.g. GIS) for both directives.

- It seems to be appropriate to have one governing (or at least coordinating) body or institution for both directives, in order to guarantee identification of synergies and conflicts, synchronised measures, pooling of resources and instruments for the implementation of measures and to avoid negative effects.

- Regional working groups including experts from national level (e.g. nature, risks, water focused) and a vertical exchange is recommended. Established groups for participation, e.g. those established within the frame of the WFD could be engaged and maybe complemented with representatives for flood risk-specific issues.

- A general recommendation for the process is that stakeholders should interact with an aim of understanding conflicting perspectives.

- Development of a long-term visionary plan by stakeholders, politicians, businesses and the general public can create a common framework for accepted activities on regional level.
Recommendation 2: Identification of site-specific synergies

- The synergies should be identified-in general and also site-specific-for the respective basin.

- A basin-wide assessment of flood reduction measures with positive effects on water quality and on ecology and/or agriculture is seen as supportive for the identification of synergetic measures. One approach could be the identification of site-specific target areas for an efficient concentration of a certain kind of measures and pooling of different implementation instruments.

- A catalogue of measures could give an overview of potential measures along different planning fields and show implications and synergies regarding objectives, measures and instruments.

- An illustration or database with examples of good practise is seen as helpful for identifying appropriate approaches.

\section{Recommendation 3: Cooperation with related fields}

- Cooperation should be conducted with related fields, such as nature conservation, agriculture and urban planning.

- By setting up the FRMP, representatives and stakeholders from all relevant (planning) fields should be consulted—or even better-included in the planning process. A catalogue of measures which shows possible FD and WFD related measures for all planning fields such as nature conservation, urban planning, agriculture or forestry could support this process.

\section{Recommendation 4: Overview of synergetic measures and implication}

- An overview of possible synergetic measures or illustration of the implications of different measures of the two directives should be provided.

- Planning instruments for the directive's implementation such as RBMP or FRMP should be used for the integrated management.

- A cooperative planning process with relevant stakeholders for both fields should be conducted. This is also helpful for identification and implementation of the respective instruments such as plans, programmes. By doing so, measures for both policies in the same area can be combined in order to maximise/optimise land use.

- It could be useful to develop a kind of modularised plan with a common part which shows the overlapping 
issues and with two different parts for each of the directives.

Before methodological approaches for IRBM will be described in "European experts' views on synergies between WFD and FD" section which considers a broad range of the recommendations, the water management situation in German will be described with regard to a. state of the WFD implementation and meeting the goals, $b$. water governance and c. a reflection of the German conditions against the of the above described recommendations.

\section{Water management situations in Germany}

Taking a look at the water situation in Germany, it becomes clear that there is still a long way to go in order to achieve the "good" status for surface as well as groundwater bodies. A largely uniform nationwide approach has been applied for the identification of pressures and impacts in the German River Basin Districts (RBD) (WRc 2015). The possibility of claiming exemptions to meet the goals has been made use of for $82 \%$ of Germany's surface water bodies as well as $36 \%$ of the groundwater bodies (Richter et al. 2013). Improvements need to be achieved in both, the ecological as well as the chemical status in natural, heavily modified and artificial water bodies. $15.5 \%$ (1.6\% very good $/ 13.9 \%$ good status) of the natural surface water bodies met the WFD targets. The remaining natural water bodies are classified as moderate $(32.5 \%)$, poor $(30.5 \%)$ or bad $(4.5 \%)$. Summed up, only $10 \%$ of Germany's surface water bodies have reached the WFD's goals (cf. Richter et al. 2013), the "good" chemical status has been reached in $88 \%$ of all surface waters and $63 \%$ of the groundwater bodies (ibid.).

Major differentiations cannot be discovered regarding the progress of measures according to pressures. Around $30 \%$ of measures have not started in the German river basins, around 50-70\% are ongoing and around 10-20\% have been completed. The situation in the ten different RBDs in Germany is largely similar: the percentage of projects on-going ranges from $73 \%$ (Eider) to $91 \%$ (Rhine). Warnow-Peene has completed $18 \%$ of its measures, the highest out of the RBD (WRc 2015).

Four hundred and fifty-nine supplementary measures were reported for the whole of Germany. For $24 \%$ of the (planned) key measures, a delay of the implementation occurred or was predicted. Missing financial and personal resources were identified as the main reason of delay, followed by a lack of acceptance of individual measures. Another challenge was faced in allocating available and suitable areas and access to land. Further delays could be ascribed to new findings in the effect of measures, technical and legal obstacles as well as changing costs (BMU 2013).

To sum up: Germany is far away from meeting the WFD goals by 2015. Although not only the delays in measure implementation can be made responsible to this situation, it becomes clear that improvements are needed in coordinated actions identifying and using cross-sectoral synergies.

Germany is a federal state with responsibilities for environmental and water aspects on the Länder (federal state) level. Since the WFD requires the establishment of authorities for water management on basin level, so called Flussgebietsgemeinschaften (river basin cooperation areas) were installed for ten river basins. However, responsibilities are still with the Länder and administrative misfits have to be considered (Moss 2012).

The WFD asked member states to replace existing institutions with river basin authorities, specifying only the need to name a competent authority responsible for coordinating all necessary activities within a River Basin District. In Germany, this has resulted in parallel structures for river basin management, with executive authority remaining in the hands of the federal states and planning procedures conducted around river basins and their sub-basins (ibid). This has avoided problems of organisational restructuring, but at the expense of significant transaction costs for new forms of coordination between state water authorities within a river basin district and between subbasins within a single state.

In order to coordinate water related issues and regulations, the Länderarbeitsgemeinschaft Wasser (LAWA) (federal working group) was established to work out recommendations, amongst others, for the implementation of European directives. Additional to distinct recommendations for each directive, LAWA published a paper about a commended approach for identification and coordination of synergies between WFD and FD (cf. Fig. 1 and LAWA 2013).

The approach is based on the adjustment of potential and proposed measures, compiled in the catalogue of measures which was published for the implementation procedure of the WFD. It comprises 107 different measures (LAWA 2008) which are related to different pressure sources (e.g. diffuse or point source) and grouped into different pressure groups such as industry, agriculture or municipalities. The respective programmes of measures (PoM) for each river basin management plan are referring to this compilation which should improve the coordination amongst the river basins and Länder. This framework is a first attempt to coordinate and adjust measures identified in the RBMP and FRMP. However, the identification of the respective required actions is analysed in parallel procedures which reduces the synergetic potential identifying 


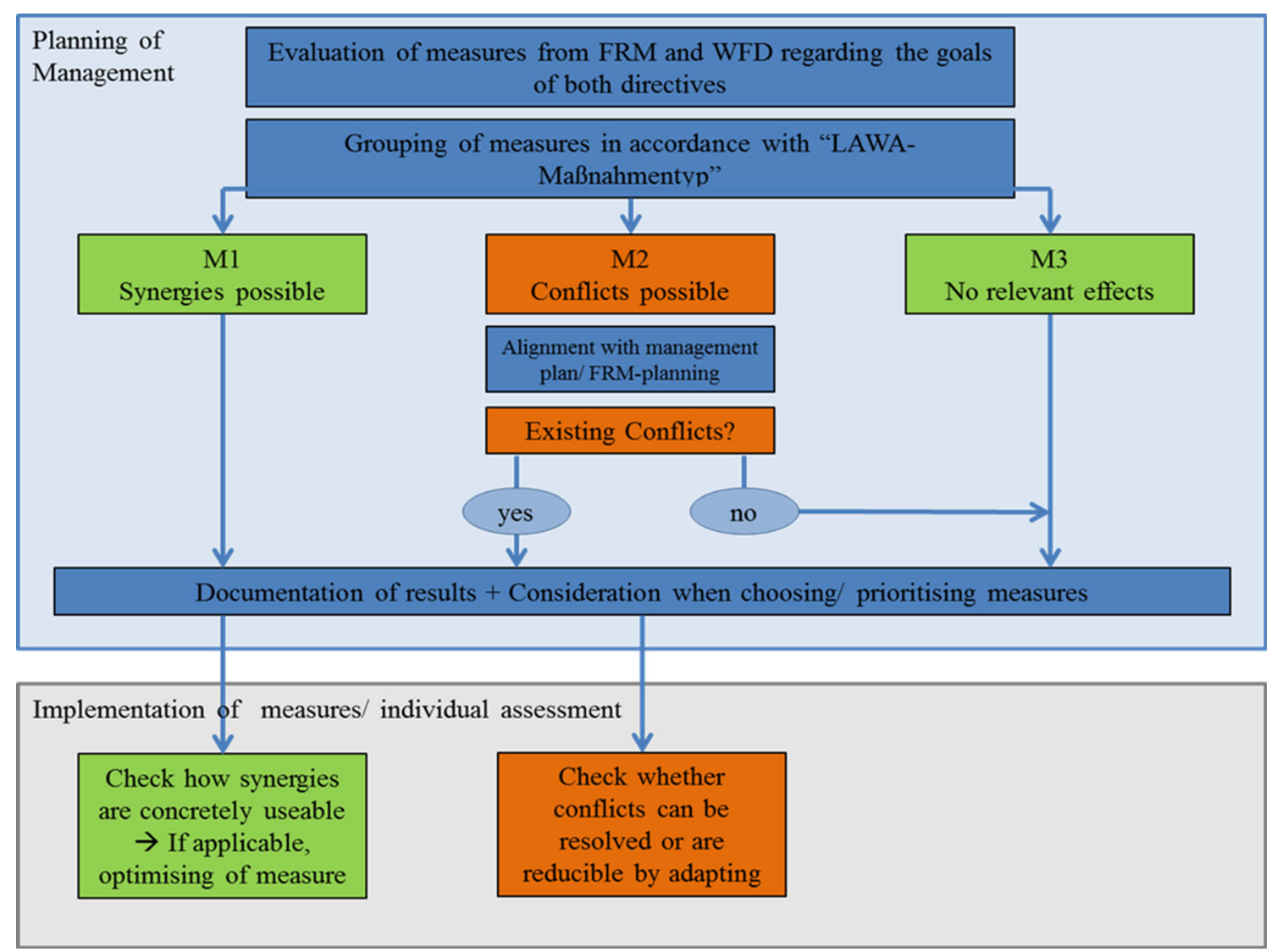

Fig. 1 Verification scheme for analysing synergies between FD and WFD (adopted from LAWA 2013)

site-specific priority targets and measures and to pool possible instruments from different fields of action.

\section{Reflection of the European expert recommendations against the German river basin management situation}

\section{Recommendation 1: Communication and coordination}

The two directives are coordinated on Länder basis with a parallel structure, the river basin cooperation areas. The competence for coordination lies with the Länder, thus on the administrative unit and not on the basin unit. The positive aspect is that flood risk management and water quality normally is coordinated mostly by one authority, the federal Ministries for Environmental Affairs. However, often different departments are responsible for WFD and FD, whether coordination is pursuit consequently depends on the individual situation. That is also the case for the coordination of data. In some Länder (e.g. in Saxony), a structure for data exchange of WFD and FD data has been established.

To implement the WFD effectively, the authorities need to cultivate close collaboration with stakeholder groups to persuade them to support the implementation effort, exploring potential synergies of interest and resolving conflicts: a largely unfamiliar task for water authorities in Germany (Moss 2012).

Participation for the WFD implementation was realised in various intensity and formats in Germany. Germany therefore can be seen as a "laboratory" in which very different forms of participation may be observed (Newig et al. 2014). The LAWA guidelines for the two directives differ substantially on the notion of participation. While the WFD guidelines adopt quite a broad notion of the public to be addressed in participatory processes, the recommendations for FRMP interpret the term "interested parties", given in Article 10 (2) of the FD, rather narrowly as "the relevant authorities involved in the drawing up and implementation of the FRMPs, municipalities, recognized associations [...and] other interest groups determined on a case-by-case basis" (LAWA 2012, p. 18).

Participation under the WFD in Germany has mainly incorporated organised interests, giving less opportunity for involvement of the wider public (Newig et al. 2014); however, in some Länder, an intense process took place. For participation for implementation of the FD-which can be seen much more relevant for participation since citizens 
as residents and property owners are potentially far more significantly and directly affected by flood management issues as compared with water management under the WFD - the requirements are much less detailed about participation, mandating even less involvement of the general public (Newig et al. 2014). Some Länder, such as Lower Saxony, explicitly denounce, the WFD approach to participation as well as any close alignment in implementing the two directives. Newig et al. (2014) found that the "baseline" level of non-state actor participation is lower in FD implementation as compared with WFD planning.

\section{Recommendation 2: Identification of site-specific synergies}

Regarding the official documents, the river basin management plans and the flood risk management plan different planning and development processes have to be stated. This is probably because of different focal goals of the two directives, different departments and expertise involved, different stakeholders, dissimilar problems, time schedules and not all basins show flood risk, thus no FRMP is required. Thus, no basin-wide assessment or site-specific identification of target sites or problem sites was conducted. However, a scheme for querying of synergies was developed and published by LAWA (2013). Yet, this step is proposed in the stage when respective WFD and FD measures are already identified and assigned. As far as known no database with good practise is existent, but some studies such as a Master Thesis on using synergies of FD, WFD and Flora-Fauna-Habitat Directive (FFH) in river restoration projects in Northrhine Westhalia were conducted (Schultz 2015).

\section{Recommendation 3: Cooperation with related fields}

Coordination of the WFD with the European Flora-FaunaHabitat Directive is required, which is realised in the German RBMP. In Article 7, the FD demands that the FRMP plans have to take relevant aspects into account, such as costs and benefits, areas with a potential for retaining flood water, such as natural floodplains, the environmental objectives of the WFD, soil and water management, spatial planning, land use, nature conservation, navigation and port infrastructure.

\section{Recommendation 4: Overview of synergetic measures and implication}

As far as the author is aware of, several studies on synergetic measures and implication are conducted by a couple of scientists, though no systematic structure or methodologies are elaborated and no general recommendation for the Länder to implement is developed.

The German example reveals the clear relevance for analysing and identifying of synergetic measures. A report which is taking stock of the current situation in Germany stresses that synergies between different approaches and directives should be used in the future (BMU 2013, p. 13).

\section{Methodological approaches for integrative river basin management}

In this section, two methodological approaches for integrative river basin management will be described. The first was developed using a case study within the above mentioned EU project SAWA. It addresses and considers quite a number of the identified aspects and recommendations of communication and coordination, identification of sitespecific synergies, cooperation with related fields and gives an overview of synergetic measures and implications. The second part will describe approaches of RBM by considering the ecosystem services approach.

\section{Integrative river basin management planning}

Using the example of the River Ilmenau river basin (which is a tributary to Elbe river) in Northern Germany, a transdisciplinary methodology was developed to identify target areas for specifying and pooling measures, with a purpose to meet the goals of both directives. By doing so, the synergetic effects were analysed and focus areas for certain measures were identified.

The approach is called integrative river basin management planning (IRBMP), which clarifies that the focus is on the process of planning by including scientists and nonscientists (experts), and not only on the end product of developed RBMP or FRMP.

For identification of action priorities and options, the working steps according to Fig. 2 were implemented. The process of identifying main target areas within a basin starts on the general, non-spatial-specific level by doing a synopsis of relevant guidelines, directives and other legally binding frameworks. Against this background, more specific goals and quality standards have to be categorised, such as protected areas or water quality standards.

Furthermore, a regional assessment of area-specific quality standards and a status quo analysis is conducted in order to identify regional deficits. This analysis is based on monitoring-data, geo-data, documents, expert interviews and workshops with experts from various fields of action such as water management, nature conservation, agriculture, spatial planning, etc. Finally, on the local level, 


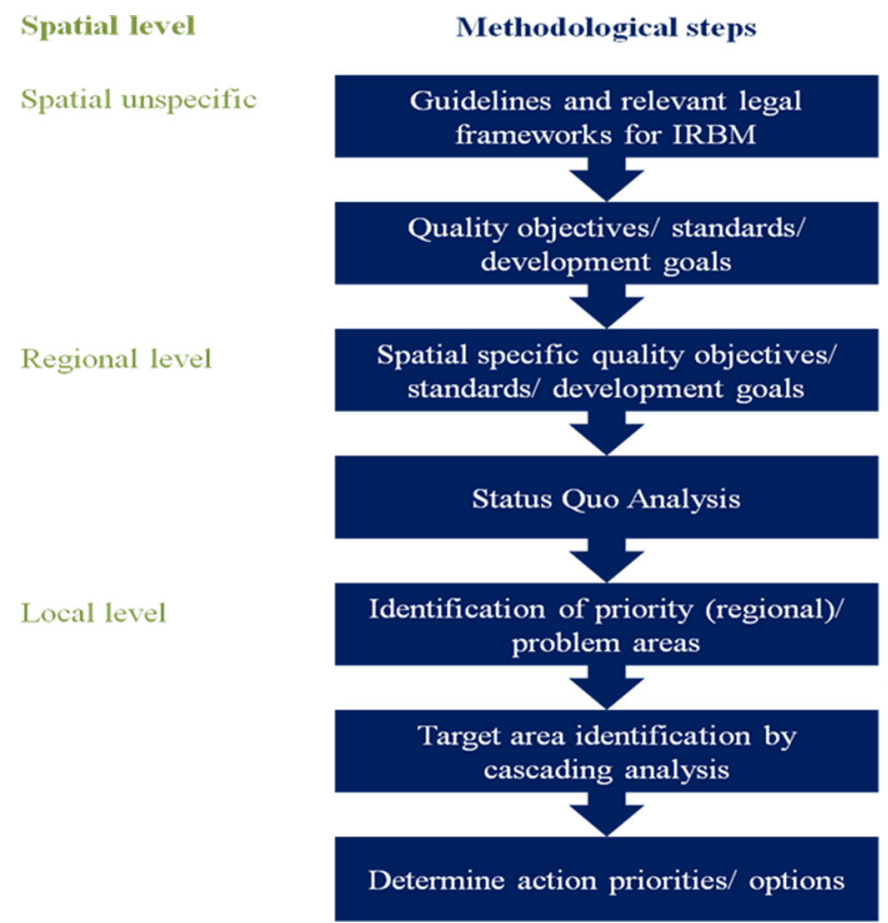

Exemplifications

$\leftarrow$ Above all: WFD, FD, FFH, German Water Resources Act (WHG), Federal Nature Conservation Act

$\leftarrow$ e.g. Good ecological state, protection and development of habitats and species

$\leftarrow$ e.g. type-specific good state, habitattarget species

$\leftarrow$ Evaluation of regional documents and plans and technical and spatial data, e.g. Inventory WFD

$\leftarrow$ Method: Target-performance-comparison, inclusion of regional expertise; Topics e.g. river stretches with flood risk, important water management issues, etc

Fig. 2 Methodology for identification of target areas

priority problem areas and target areas are analysed by cascading GIS queries and specific actions and related measures are identified.

IRBMP supports improvements of coordination and implementation processes in IRBM, with the aim to promote flood mitigation and improvement of water quality (Evers 2014).

The IRBMP contains a series of maps which are compiled in a digital river basin atlas. Based on these, the river basin atlas further contains.

- Distributed data and information of the various sectoral plans (e.g. from water management, conservation, spatial planning and agriculture) are collected, visualised and made available to the professional public;

- Synergy and conflict potentials between the spatiallyrelevant plans are presented;

- The pooling of resources is supported through prioritisation of measures.

The following procedure was conducted to generate the IRBMP:

(1) Providing the basis for trans-sectoral basin-based coordination and planning:

- GIS-based spatial analysis for identification of relevant targets;
- Development of a basin-based atlas in pdf-format with geo-referenced maps and background information on data and applied methodologies;

- Preparation of data and the current action plan in line with international standards (Open Geospatial Consortium-OGC) to enable data exchange and compatibility.

(2) Target Area Analysis

- Identification of target areas where measures are prioritised and pooled. The principle of the target area analysis is by means of the intersection of several thematic maps in GIS (as done like illustrated in Fig. 4 producing maps such as for retention capacity, Fig. 3), focusing on areas that are especially relevant to the particular analysis and therefore worth to be considered as potential areas for the implementation of measures. Through the query in several steps, the cascading analysis, areas can be narrowed down further and further until the target areas for focussing measures finally are covered;

- Recommendations and prioritisation of measures on basin level together with key stakeholders (technical authorities of different levels, experts);

- Identification of fields of action and measures based on the spatial analysis and the package of 


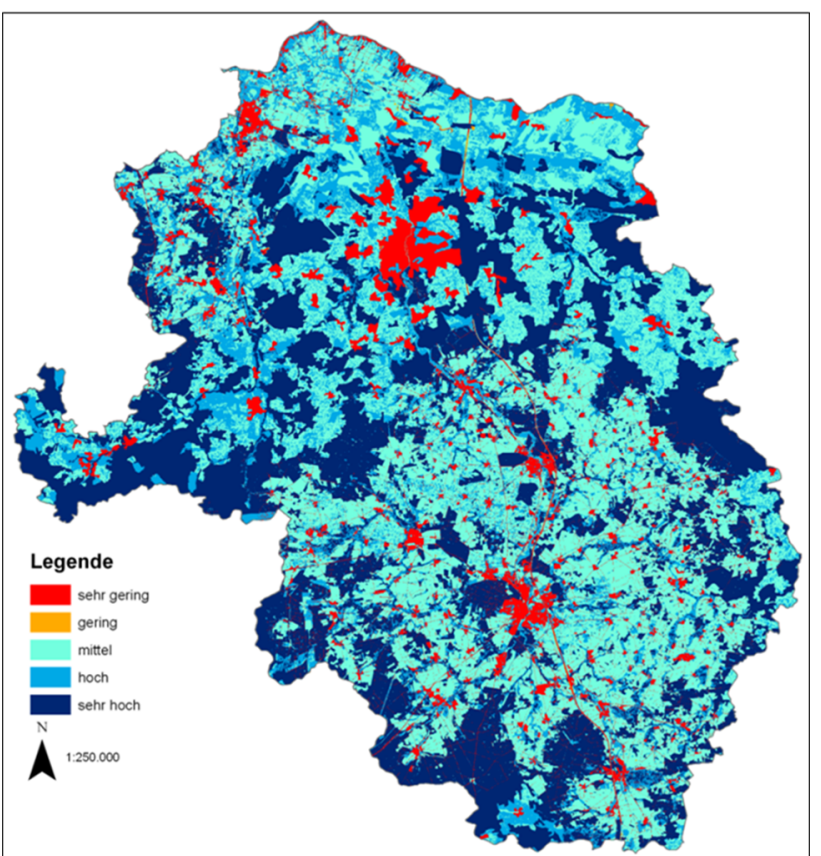

Fig. 3 Result of the analysis of retention capacity of the catchment area of the River Ilmenau

measures for a preventive flood risk management.

(3) Catalogue of measures jointly developed in a participatory process with stakeholders and experts from different fields of action such as water management, agriculture, nature conservation. The catalogue is structured along types of measures and related or responsible fields of action.

Using this approach, a comprehensive overview of the main problem areas for the basin area can be identified quickly and with relatively little effort. The analysis of the retention potential is an important result and the basis for further analysis. From the representation of multiple target area analysis results, synergies can also be derived.

This information is processed and provided via a basinbased atlas in pdf-format with geo-referenced maps. The different layers of these maps can be made visible or invisible by clicking on the respective layer. The atlas also contains background information on data and applied methodologies and some information on predicted regional climate change data.

\section{Including ecosystem services approaches in RBM}

Reyjol et al. (2014) state that to date Ecosystem Services Approach (ESA) is not clearly used by water managers when designing the programmes of measures, even if some examples exist. They claim that the adoption of the ESA is of importance in terms of river basin management. The Millennium Ecosystem Assessment (MEA 2003) regards ecosystem services as services produced and provided by ecosystems and distinguishes them into the following types: (1) supporting services (such as water cycle), (2) provisioning services (as provision of drinking water), (3) regulating services (as retention of water or nutrients) and (4) cultural services (e.g. recreation). The crucial characteristic of the ESA is an anthropocentric perspective stating that ecosystems provide services to human beings. The concept and especially the different approaches for monetarisation of and payments for Ecosystem Services are intensively debated. However, the ESA can provide an opportunity to bring together scientists working across different disciplines (e.g. ecologists and economists) and makes available a practical and useful common language that can be used independently by politicians, scientists, water managers and citizens, in a sustainable development perspective (Reyjol et al. 2014).

Against the background of landscape multifunctionality Galler et al. (2015) developed a methodology for optimising
Fig. 4 Example of a cascading analysis-here to identify the most suitable areas for increasing retention capacity in the flood plain

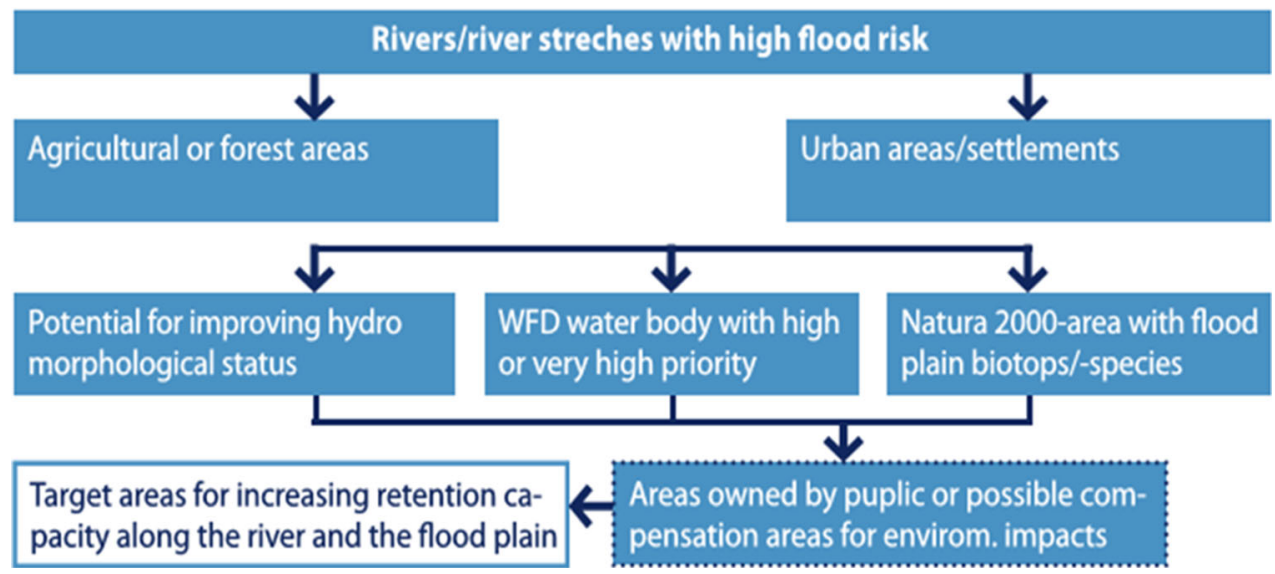


environmental measures where a range of ecosystem services were quantified and space specifically identified. The assumption for this approach is that implementing multifunctional measures that are supportive to several ES can enhance the implementation effectiveness and efficiency of public spending. They developed integrative management strategies that exploit synergies from implementing multifunctional measures by the need to quantify expected management effects on different ecosystem services.

Furthermore, the authors created sectoral baseline and alternative scenarios for optimised implementation of sectoral measures such as erosion prevention, safeguarding water quality, climate change mitigation and safeguarding biodiversity as well as integrative baseline scenarios. The scenarios were developed for the county Verden on the basis of data from a landscape framework plan.

Alternative scenarios were optimised against following premises: (1) scenario alternatives with limited financial resources, (2) equal distribution of 40 Mio. $€$ within the environmental sectors and (3) a spatially optimised integrative strategy. The result of the case study was that the highest total environmental benefit per hectare can be achieved by a spatially optimised integrative strategy. Neither a cost-optimised integrative strategy nor uncoordinated sectoral management strategies achieve comparable spatial efficiency. However, when the budget is limited, optimising spatial efficiency leads to a comparably small sum of total objective fulfilment (Galler et al. 2015).

This approach was applied at an administrative scale (the county unit), thus it is not congruent with WFD/FD units. However, it seems to be applicable also at a basin scale, because a lot of required information and data are available due to extensive work for WFD implementation.

Reyjol et al. (2014) argue that water managers need to become able to identify all the ES at the basin, sub-basin and water body scales, as this will allow more integrated management of resources by implementing the WFD and FD. This offers opportunities to overcome key barriers, such as just following a sectoral approach. Further, this approach offers potential as a communication vehicle for WFD and FD objectives as well as for needs for measures which can create better acceptance of measures.

However, until now a consequent applied ESA in WFD and FD management is not in place.

\section{Summary and discussion}

River basin management can be considered as the integration of planning and management of water resources, sustainable development and strategies on a river basin level. Mainly two European directives, the WFD and the FD are framing the management of river basins in the
European Union. There is clear evidence of synergies between these two directives. Based on the literature, documents and elicitation of expert views based on questionnaire and a conference session dealing with this topic, synergies and recommendations how to deal with these synergies were identified.

There is still a lack in the successful implementation of the measures within the scope of the WFD in order to reach the directive's goals in Germany. Reasons are missing financial and personal resources, lack of acceptance, or challenges in allocating available and suitable areas.

Further challenges arise within the scalar tensions in responsibilities: while environmental and water aspects are traditionally governed in Germany on a federal level, the new directives requires the implementation of coordinating institutions at the basin level. Responsibilities are still with the federal states and administrative misfits have to be considered.

While the LAWA scheme for querying synergies was developed, this is merely proposed for a step when respective WFD and FD measures are already identified and assigned in the RBMP/programme of measures. Thus, measures described and appointed for the FRMP are identified in parallel procedures. The identification of basin-wide or site-specific synergies is not pursuit which reduces the potential for synergetic measures and pooling possible instruments from different fields of action.

While there are existent studies in Germany how synergies are used for IRBM, no systematic structure or methodologies seem to have been elaborated and no general recommendation for the federal states to implement has been developed so far.

Based on theoretical considerations and European experts' recommendations, a methodological frame was developed for the IRBM approach by using a case study in the Ilmenau river basin in Germany. The IRBM approach is based on two tools and the coordinated transdisciplinary process of their development. One tool is a plan, which is actually a series of basic information such as retention capacities in the river basin, environment qualities or planned activities. There is also a number of maps, generated by cascading GIS-analyses which are showing target areas for measures for improving water/environmental quality and reduction of flood risk on the basin scale. These maps are gathered in a digital atlas. The other tool is a catalogue of measures which shows a series of measures structured along different planning and management sectors. By structuring them along themes and responsibilities, an overview is given not only for possible measures and perspective implementation measures, but it is also showing clear synergies between different sectors (e.g. between water management, spatial planning, agriculture).

The output and information from these trans- and interdisciplinary developed planning tools can be 
integrated in all relevant plans and programmes such as river basin management plans, flood risk management plans, but also in spatial planning or master plans as well as incentive programmes e.g. in agriculture. By doing so, different instruments can be pooled for implementing coordinated measures in a more effective and efficient way.

Another approach is the identification of Ecosystem Services and optimising measures. The ESA was only introduced briefly in this paper although an intense discourse about it is going on. However, the author thinks that the ESA is worth to consider in the context of IRBM. Against the background of landscape multifunctionality, a methodology for optimising environmental measures which was developed by colleagues from University of Hanover is described where a range of ecosystem services were quantified and site-specifically identified. The approach shows integrative management strategies that exploit synergies from implementing multifunctional measures by the need to quantify expected management effects on different ecosystem services. In the case study area, this approach was applied at an administrative (the county unit). In order to overcome the spatial misfits with the RBM, it should be applied at a basin scale. Much data are available on river basin scale due to extensive work for WFD implementation, thus this approach seems to be implementable.

It would be worth to develop these two discussed approaches further in order to combine relevant and important aspects. With regard to the shortcomings in Germany, concerning meeting the goals of the WFD and problems of implementation of measures for improvement these are mainly: (1) Identification of space-specific target areas for WFD and FD, (2) Identification of ES on the river basin scale, (3) Prioritisation of measures, (4) Identification and appointment of different instruments for measure implementation to use synergies in order to minimise resources and need for space, (5) Propagation of transdisciplinary/participatory processes which can create better acceptance of measures. This is even more important if we consider the following quote from an interview partner in the Elbe basin:

'When it comes down to it, what happens in the river basins is the sum of what actors are doing within the legal framework; but the legal framework alone does not control the actions'.

Acknowledgements The study was partly funded by the EU project Strategic Alliance of Water Management Actions (SAWA). I like to thank Lars Nyberg for his valuable feedbacks and reflexions on the paper's topic during various discussions.

Open Access This article is distributed under the terms of the Creative Commons Attribution 4.0 International License (http://crea tivecommons.org/licenses/by/4.0/), which permits unrestricted use, distribution, and reproduction in any medium, provided you give appropriate credit to the original author(s) and the source, provide a link to the Creative Commons license, and indicate if changes were made.

\section{References}

Bandaragoda DJ, Babel MS (2010) Institutional development for IWRM: an international perspective. Int J River Basin Manag 8(3-4):215-224. doi:10.1080/15715124.2010.496707

BMU (2013) Die Wasserrahmenrichtlinie. Eine Zwischenbilanz zur Umsetzung der Maßnahmenprogramme 2012. Berlin. https:// www.umweltbundesamt.de/sites/default/files/medien/378/publika tionen/wasserrahmenrichtlinie_2012.pdf Accessed 10 Oct 2015

EC (Commission of the European Communities) (1992) Directive 92/43/EEC 92/43/EEC of 21 May 1992 on the conservation of natural habitats and of wild fauna and flora. Brussels

EC (Commission of the European Communities) (2000) Directive 2000/60/EC of the European Parliament and of the Council establishing a framework for the Community action in the field of water policy-The EU Water Framework Directive-integrated river basin management for Europe. Luxembourg

EC (Commission of the European Communities) (2007) Directive 2007/60/EC of the European Parliament and of the Council of 23 October 2007 on the assessment and management of flood risk. Strasbourg

EC (Commission of the European Communities) (2014) Links between the floods directive (FD 2007/60/EC) and water framework directive (WFD 2000/60/EC). Tech Rep. doi:10. $2779 / 71412$

Evers M (2014) Integratives Flussgebiets- und Hochwasserrisikomanagement-synergien identifizieren und nutzen. KW Korrespondenz Wasserwirtschaft. doi:10.3243/kwe2014.08.004

Evers M, Nyberg L (2013) Coherence and inconsistency of European instruments for integrated river basin management. Int J River Basin Manag 11(2):139-152. doi:10.1080/15715124.2013. 811416

Galler C, von Haaren C, Albert C (2015) Optimizing environmental measures for landscape multifunctionality: effectiveness, efficiency and recommendations for agri-environmental programs. J Environ Manag 151:243-257. doi:10.1016/j.jenvman.2014.12. 011

Griffith M (2002) The European Water Framework Directive: an approach to integrated river basin management. Eur Water Manag Online. European Water Association (EWA), Brussles

Holzwarth F (2002) The EU Water Framework Directive-a key to basin-based governance. Water Sci Technol 45(8):105-112

LAWA (2013) Empfehlungen zur koordinierten Anwendung der EGHWRM-RL und EG-WRRL. Potenzielle Synergien bei Maßnahmen, Datenmanagement und Öffentlichkeitsbeteiligung, Magdeburg

LAWA (German Working Group on Water Issues of the Federal States and the Federal Government) (2008) Maßnahmenkatalog

LAWA (German Working Group on Water Issues of the Federal States and the Federal Government) (2012) Grundsatzpapier zur Öffentlichkeitsbeteiligung im Zuge der Umsetzung der HWRMRL. LAWA, Ständigen Ausschusses Hochwasserschutz und Hydrologie, Magdeburg

MEA (2003) Ecosystems and human well-being: a framework for assessment. http://millenniumassessment.org/en/index.html. Accessed 10 Oct 2015

Moss T (2012) Spatial fit, from panacea to practice: implementing the EU Water Framework Directive. Ecol Soc. doi:10.5751/ES04821-170302 
Mostert E, Junier SJ (2009) The European flood risk directive: challenges for research. Hydrol Earth Syst Sci Discuss 6:4961-4988

Newig J, Challies E, Jager N, Kochskämper E (2014) What role for public participation in implementing the EU floods directive? A comparison with the water framework directive, early evidence from germany and a research agenda environmental policy and governance. Environ Pol Gov. doi:10.1002/eet.1650

Reyjol Y, Argillier C, Bonne W, Borja A, Buijse AD, Cardoso AC, Daufresne M, Kernan M, Ferreira MT, Poikane S, Prat N, Solheim A, Stroffek S, Usseglio-Polatera P, Villeneuve B, van de Bund Wouter (2014) Assessing the ecological status in the context of the European Water Framework Directive: where do we go now? Sci Total Environ 497-498:332-344. doi:10.1016/j. scitotenv.2014.07.119

Richter S, Völker J, Borchardt D, Mohaupt V (2013) The Water Framework Directive as an approach for integrated water resources management: results from the experiences in Germany on implementation, and future perspectives. Environ Earth Sci 69(2):719-728. doi:10.1007/s12665-013-2399-7

Schultz A-K (2015) FFH-/Vogelschutzrichtlinie, Wasserrahmenrichtlinie und Hochwasserrisikomanagement-Richtlinie-Synergien und Konflikte bei der Planung und Durchführung von Renaturierungsmaßnahmen an Fließgewässern in NordrheinWestfalen. Masterthesis at University of Bonn (not published)

UNECE (1992) Convention on the protection and use of transboundary watercourses and international lakes done at Helsinki, on 17 March 1992. UNECE, Helsinki

WRc (2015) Assessment of Member States' progress in the implementation of Programmes of Measures during the first planning cycle of the Water Framework Directive. Member State Report, Germany

WWF (World Wildlife Fund) (2003) Lessons from WWF's work for integrated river basin management: In: Managing Rivers Wisely. http://www.panda.org/about_wwf/what_we_do/freshwater/our_ solutions/rivers/irbm/index.cfm. Accessed 25 Sept 2015 